\title{
Alterações morfológi cas da curvatura menor do estômago após gastrectomia segmentar associada à vagotomia gástrica proximal. Estudo experimental em cães.
}

\author{
L. M. Watanabe, J . I. Andrade, F. F. C. Neto, R. Cenneviva
}

Trabal ho realizado no Laboratório de Cirurgia Experimental do H ospital das Clínicas da F aculdade de M edicina da U niversi dade de São Paulo, Ribeirão Preto, SP.

RESUMO - A ressecção segmentar do corpo gástrico, também denominada gastrectomia segmentar (GS), foi associada à vagotomia gástrica proximal (VGP) para o tratamento das úlceras duodenais, principalmente para os pacientes com maior risco de recidiva ulcerosa.

Ов етіvo. Avaliar as alterações histopatológicas da curvatura menor do estômago decorrentes da associação da GS à VGP.

Métodos. Foram utilizados 36 cães com peso corporal entre 10 e $20 \mathrm{~kg}$, distribuídos em três grupos: Grupo I (controle) - animais submetidos à laparotomia e mani pulação gástrica; Grupo II ani mais submetidos à VGP; e Grupo III - ani mais submetidos à GS associada à VGP. Cada grupo foi dividido em dois subgrupos de seis animais, sendo os animais do primeiro e do segundo subgrupos sacrificados no terceiro e no oitavo dia pós-operatório, respectivamente. Para o estudo microscópico, procedeu-se a retirada de fragmento retangular da curvatura menor de cada estômago.

Resultados. Com base na comparação dos indi-

\section{NTRODUÇÃO}

A pós três décadas da ampla utilização da vagotomia gástrica proximal (VGP) no tratamento da doença ulcerosa duodenal, diversos estudos prospectivos e casualizados demonstraram que esta operação é um procedimento seguro $0^{1,2,3}$, com baixa taxa de mortalidade operatória ${ }^{2,3}$ e índice mínimo de seqüelas pós-operatórias 3,4. Todavia, embora seja a operação de maior benignidade, a recorrência ulcerosa tem sido o fator crítico da VGP. Diferentes grupos de pesquisadores têm relatado índices divergentes de recidiva ulcerosa após VGP, compreendendo desde valores adequados inferiores a $10 \% 5,6$, incluindo valores menos aceitáveis de 10 a $20 \% 4,7$, até taxas inadmissíveis, superiores a $20 \% \%^{8,9,10}$.

E $m$ virtude dos resultados discrepantes quanto à recorrência ulcerosa, Ceneviva ${ }^{11}$ propôs a associação da ressecção segmentar do corpo gástrico cadores histopatológicos entre os subgrupos de animais sacrificados no mesmo dia, incluindo edema, congestão vascular, exsudato inflamatório, fibrose e dano celular, verificou-se que estas alterações microscópicas foram infreqüentes e leves no grupo I, freqüentes e moderadas no grupo II e constantes e intensas no grupo III. E mbora inespecíficos, os achados histopatológicos foram semel hantes quanto à natureza e ao local de acometimento intramural, com os processos isquêmicos. Foi observado também uma relação diretamente proporcional entre a gravidade das alterações morfológicas e os procedimentos cirúrgicos de maior potencial isquêmico.

Conclusão. A gastrectomia segmentar possivelmente agravou o suprimento sangüíneo arterial da parte remanescente da curvatura menor do estômago, já previamente comprometida pela desvascularização conseqüente à vagotomia gástrica proximal.

UNITERMOS: Gastrectomia. Vagotomia gástrica proximal . Úlcera duodenal. (gastrectomia segmentar) (GS) à VGP, para o tratamento das úlceras duodenais, sobretudo naqueles pacientes com maior risco de recidiva. Em estudos posteriores foi demonstrado que a VGP associada à GS promoveu redução significativamente maior na produção máxima de ácido, sem modificação substancial na vel ocidade de esvaziamento gástrico para líquidos ${ }^{12}$ e para sólidos ${ }^{13}$, como também, sem aumento significativo no refluxo enterogástrico ${ }^{14}$, em comparação com a VGP isolada. A médio prazo foram relatados menores índices de recidiva ulcerosa ${ }^{15}$.

Todavia, Nilsell et al. ${ }^{16}$ relataram a ocorrência de deiscência de anastomose na curvatura menor, em paciente submetido à GS associada à VGP. Esses autores sugeriram como fator causal a deficiência do suprimento sangüíneo secundária à desvascularização gástrica, decorrente desse tipo de vagotomia. Entretanto, a falha técnica na execução da anastomose não pôde ser afastada. Após 
cuidadosa revisão da literatura, observou-se ausência de dados a propósito das possíveis conseqüências da associação de GS à VGP sobre a vascularização arterial dessa região.

A presente investigação tem por objetivo analisar as alterações morfológicas da curvatura menor em cães submetidos à GS associada com VGP.

\section{MATERIAL E MÉTODO}

F oram utilizados 36 cães adultos, mestiços, com peso corporal entre 10 e $20 \mathrm{~kg}$, distribuídos por sorteio em três grupos de 12 animais, com as seguintes denominações: Grupo I - animais do grupo controle; Grupo II - animais submetidos à VGP; e Grupo III - animais submetidos à VGP + GS. Após jejum de 24 horas, os cães foram anestesiados com pentobarbital sódico na dose de $30 \mathrm{mg} / \mathrm{kg}$ de peso corporal, por via intravenosa, e operados de acordo com o procedimento cirúrgico referente ao grupo sel ecionado. O acesso à cavidade abdominal foi feito mediante laparotomia mediana supra e infra-umbilical.

Os animais do grupo II foram submetidos à VGP, conforme a técnica original proposta por Griffith \& Harkins ${ }^{17}$, modificada por Goligher ${ }^{18}$. Nos animais do grupo III, além da VGP, procedeuse a realização da GS com ressecção de todo, ou quase todo, corpo gástrico, segundo a padronização técnica proposta por CENEVIVA ${ }^{11}$. A anastomose gástrica término-terminal, de boca total, foi realizada por chuleio simples contínuo, em plano único, incluindo toda a espessura da parede gástrica, com fio de polipropileno 3-0.

Nos animais do grupo I, o estômago foi mantido sob tração manual, simulando a realização de VGP, durante período de 30 minutos.

Ao final de cada operação, imediatamente após o fechamento da cavidade abdominal, os cães de cada grupo foram distribuídos, também por sorteio, em subgrupos de seis animais, denominados I-3, I-8, II-3, II-8, III-3 e III-8. As inscrições "3" e " 8 " determi navam a data do sacrifício dos animais no terceiro e no oitavo dia pós-operatório, respectivamente.

No dia previsto para o sacrifício, os cães foram novamente anestesiados, submetidos à incisão mediana tóraco-abdominal para remoção da peça, constituída pelo terço distal do esôfago, estômago e terço proximal do duodeno. O estômago foi aberto pela curvatura maior, estendido e preso com alfinetes sobre folha de cortiça, sendo então imerso em solução de formol a $10 \%$.

No exame macroscópico, as faces serosa e mucosa do estômago foram inspecionadas, com especial atenção para as eventuais alterações na área desvascularizada dos cães submetidos à VGP e, adicionalmente, na anastomose gástrica términoterminal dos animais submetidos à VGP + GS. Para o exame microscópico, retirou-se um fragmento retangular ao longo da curvatura menor de cada estômago, a cerca de $0,5 \mathrm{~cm}$ abaixo da junção esofagogástrica, medindo $1 \mathrm{~cm}$ de largura por $3 \mathrm{~cm}$ de comprimento. Nos animais do grupo III, esse fragmento não incluiu a área da anastomose gástrica.

F oram sel ecionados cinco cortes histológicos de $5 \mathrm{~mm}$ de espessura de cada fragmento, corados pela técnica de hematoxilina e eosina e pelo método tricrômico de Masson.

O estudo histopatológico foi realizado mediante microscopia óptica, por observador (FFCN) que desconhecia a que subgrupos de animais pertencia o material. Foram avaliadas as seguintes alterações teciduais: (a) congestão vascular; (b) edema; (c) exsudato inflamatório; (d) fibrose; e (e) dano celular. Cada uma destas al terações foi classificada quanto à localização nas camadas mucosa, submucosa e muscular; e quanto à intensidade em quatro graus: ausente (-); leve (+); moderada (++); e intensa (+++). Os critérios para determinação da intensidade da congestão vascular foram a dilatação pronunciada e o ingurgitamento das arteríolas e dos capilares. O edema e o exsudato inflamatório foram avaliados pelo caráter focal ou difuso e pelo grau de dissociação dos componentes teciduais.

A atividade proliferativa de fibroblastos e a densidade dos depósitos de fibras colágenas constituíram os parâmetros de avaliação da intensi dade da fibrose. A avaliação do dano celular foi realizada com base na intensidade da lesão das fibras musculares, empregando-se o seguinte critério: ausente (-); atrofia de fibras musculares (+); degeneração de fibras musculares associada à presença de tecido de reparação (++); e tecido de reparação em substituição ao plano muscular $(+++)$.

A intensidade de cada alter ação histopatológica foi comparada estatisticamente apenas entre os subgrupos de animais sacrificados no mesmo dia. Foi realizada também uma análise comparativa dentro de cada grupo, pela confrontação dos indicadores histopatológicos dos animais sacrificados no terceiro com os observados no oitavo dia pósoperatório, para determinar os aspectos evolutivos das alterações microscópicas. Para comparação dos resultados foi utilizado o teste exato de Fischer ${ }^{19}$, sendo considerados significativos os valores de $p<0,05$. 
Tabela 1 - Edema* (E) e congestão vascular (CV) da curvatura menor do estômago dos animais pertencentes aos grupos I, II e III, sacrificados no terceiro e oitavo dia pós-operatório. Os animais são representados pelos números de 1 a 6 .

\begin{tabular}{|c|c|c|c|c|c|c|c|c|c|c|c|c|}
\hline \multicolumn{13}{|c|}{ Subgrupos } \\
\hline & \multicolumn{2}{|c|}{ I-3 } & \multicolumn{2}{|c|}{ I-8 } & \multicolumn{2}{|c|}{ II-3 } & \multicolumn{2}{|c|}{ II-8 } & \multicolumn{2}{|c|}{ III-3 } & \multicolumn{2}{|c|}{ III-8 } \\
\hline 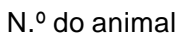 & $E$ & CV & $E$ & $\mathrm{CV}$ & E & CV & $E$ & $\mathrm{CV}$ & E & CV & E & $\mathrm{CV}$ \\
\hline 1 & - & - & ++ & + & ++ & ++ & ++ & +++ & +++ & +++ & +++ & +++ \\
\hline 2 & + & - & + & + & ++ & ++ & ++ & +++ & ++ & +++ & +++ & +++ \\
\hline 3 & + & + & + & + & +++ & ++ & ++ & +++ & +++ & ++ & ++ & +++ \\
\hline 4 & ++ & - & ++ & ++ & +++ & ++ & ++ & ++ & +++ & +++ & ++ & +++ \\
\hline 5 & ++ & - & + & - & +++ & + & ++ & ++ & +++ & +++ & ++ & +++ \\
\hline 6 & ++ & - & - & - & ++ & ++ & ++ & ++ & +++ & +++ & ++ & +++ \\
\hline
\end{tabular}

Tabela 2 - Exsudato inflamatório *(EI) e fibrose *(F) da curvatura menor do estômago dos animais pertencentes aos grupos I, ll e III, sacrificados no terceiro e oitavo dia pós-operatório. Os animais são representados pelos números de 1 a 6 .

\begin{tabular}{|c|c|c|c|c|c|c|c|c|c|c|c|c|}
\hline \multicolumn{13}{|c|}{ Subgrupos } \\
\hline & \multicolumn{2}{|c|}{ I-3 } & \multicolumn{2}{|c|}{$1-8$} & \multicolumn{2}{|c|}{ II-3 } & \multicolumn{2}{|c|}{ II-8 } & \multicolumn{2}{|c|}{ III-3 } & \multicolumn{2}{|c|}{ III-8 } \\
\hline 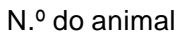 & $\mathrm{EI}$ & $\mathrm{F}$ & $\mathrm{EI}$ & $\mathrm{F}$ & $\mathrm{EI}$ & $\mathrm{F}$ & $\mathrm{El}$ & $\mathrm{F}$ & El & $\mathrm{F}$ & EI & $\mathrm{F}$ \\
\hline 1 & - & - & - & - & + & - & + & + & +++ & + & - & +++ \\
\hline 2 & - & - & - & - & ++ & - & ++ & + & - & ++ & - & ++ \\
\hline 3 & - & - & - & - & + & - & ++ & ++ & - & +++ & - & +++ \\
\hline 4 & - & ++ & - & - & + & - & - & ++ & +++ & +++ & - & +++ \\
\hline 5 & - & - & - & - & + & - & +++ & - & + & +++ & - & +++ \\
\hline 6 & - & - & - & - & + & - & - & ++ & +++ & +++ & - & +++ \\
\hline
\end{tabular}

\section{RESULTADOS}

Os animais do grupo I não apresentaram anormalidades ao exame macroscópico do estômago. No exame macroscópico dos animais do grupo II, observou-se apenas edema da mucosa da curvatura menor do estômago. No grupo III, a anastomose gástrica estava íntegra em todos os animais. F oram observados também edema e áreas hemorrágicas nas mucosas gástricas adjacentes ao local da anastomose, e ao longo da curvatura menor. As alterações macroscópicas foram sempre mais acentuadas nos animais sacrificados no terceiro dia pósoperatório e, dentre os animais gastrectomizados, no lado do coto gástrico proximal.

As seguintes alterações microscópicas foram observadas na curvatura menor, incluindo edema, congestão vascular, exsudato inflamatório e fibrose (Figuras 1, 2, 3 e 4). Os resultados do exame microscópico dos cortes histológicos da curvatura menor do estômago dos seis subgrupos de animais estão relacionados nas Tabelas 1 e 2. Dano celular de grau intenso foi observado apenas nos seis animais do subgrupo III-3.

Cotejando-se os resultados dos três subgrupos de animais sacrificados no terceiro dia, observouse diferença estatisticamente significativa para todos os parâmetros analisados: edema $(p=0,03)$, congestão vascular $(p<0,001)$, exsudato inflama- tório ( $p<0,001)$, fibrose ( $p<0,001)$ e dano celular ( $p<0,001)$.

$\mathrm{Na}$ comparação realizada entre os animais dos subgrupos I-8, II-8 e III-8, verificou-se também diferença significativa para edema $(p=0,01)$, congestão vascular $(p<0,001)$, exsudato inflamatório $(p=0,01)$ e fibrose $(p<0,001)$.

Com base na análise dos parâmetros histopatológicos, observou-se que as alterações foram infreqüentes e leves no grupo I, freqüentes e moderadas nos subgrupos do grupo II, e constantes e intensas nos subgrupos do grupo III, tanto para os animais sacrificados no terceiro quanto no oitavo dia. As alterações morfológicas da curvatura menor do estômago ocorreram principalmente nas camadas mucosa e submucosa adjacente e, menos freqüentemente, na camada muscular.

Quanto ao edema, observou-se que a mucosa foi a única camada acometida nos animais do grupo I, enquanto nos animais dos grupos II e III, além da mucosa, as camadas submucosa e muscular foram também freqüentemente envolvidas pelo edema.

Comparando entre si os grupos de animais sacrificados no terceiro e oitavo dias, houve persistência ou acentuação da congestão vascular nos animais dos subgrupos II-8 e III-8, quando cotejados com os animais dos subgrupos $1 \mathrm{I}-3$ e III-3, respectivamente.

O exsudato inflamatório mostrou-se freqüente- 


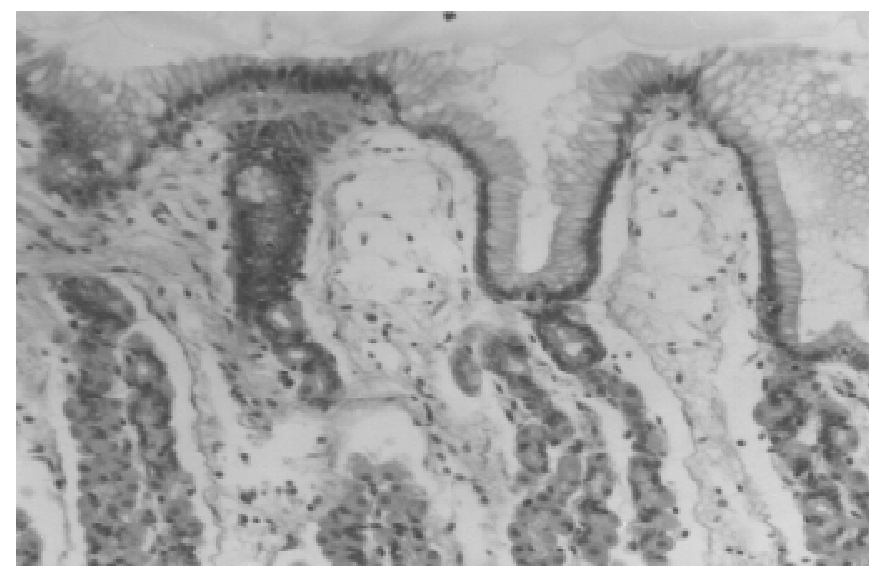

Fig. 1 - Fotomicrografia da camada mucosa da curvatura menor do estômago (H.E., 250X). Edema acentuado da mucosa gástrica $(+++)$, observado no animal 5 do grupo III, sacrificado no terceiro dia pós-operatório.

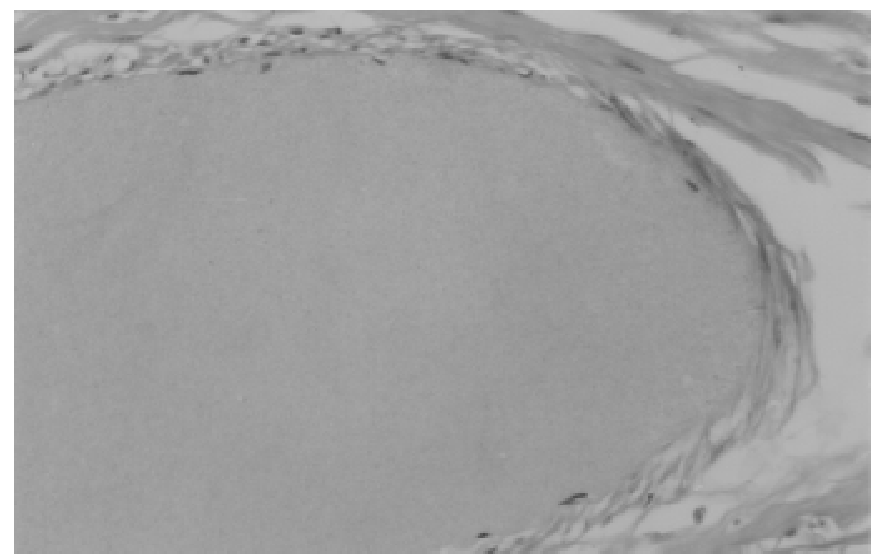

Fig.2 - Fotomicrografia da camada submucosa da curvatura menor do estômago (H.E., 400X). Congestão vascular intensa $(+++)$, observada no animal 2 do grupo III, sacrificado no oitavo dia pós-operatório.

mente de caráter focal, porém em alguns animais foi observado ao longo de extensas áreas da camada mucosa.

A fibrose, com aspecto focal ou difuso, foi observada em todos os animais dos subgrupos do grupo III, e na maioria do subgrupo II-8. Comparativamente, a fibrose foi mais freqüente e mais intensa nos animais sacrificados no oitavo dia pós-operatório, quando confrontados com os animais sacrificados no terceiro dia pós-operatório. Por outro lado, o edema, o exsudato inflamatório e o dano celular foram mais acentuados nos animais dos subgrupos sacrificados no terceiro dia pós-operatório.

\section{DISCUSSÃO}

No presente estudo, o emprego do chuleio simples contínuo, em plano único na anastomose gástrica término-terminal, foi proposital para reduzir

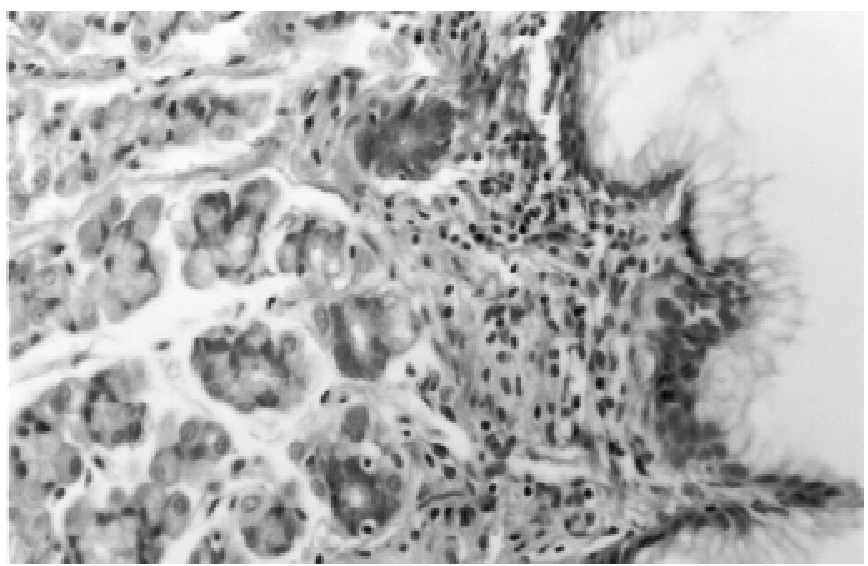

Fig. 3 - Fotomi crografia da camada mucosa da curvatura menor do estômago (H.E., 250X). Infiltrado inflamatório intenso (++), observado no animal 5 do grupo II, sacrificado no oitavo dia pós-operatório.

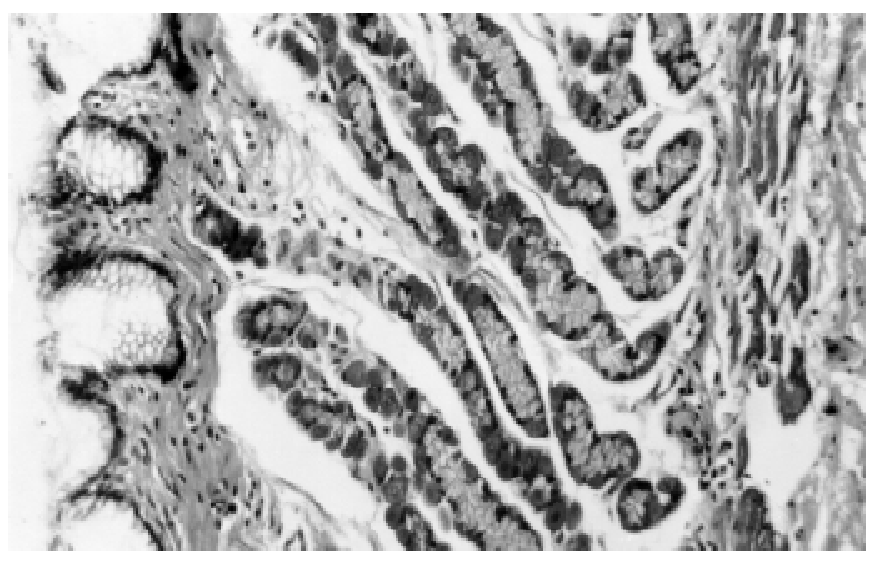

Fig.4 - Fotomi crografia da camada mucosa da curvatura menor do estômago (tricrômico de Masson, 250X). Fibrose intensa e difusa atingindo a mucosa e submucosa $(++)$, observada no animal 6 do grupo 111 , sacrificado no oitavo dia pós-operatório.

as complicações isquêmicas eventuais por interferência da sutura na circulação da região anastomótica e da curvatura menor do estômago. O chuleio simples contínuo em plano único distribui melhor a tensão na linha de sutura, com menor perigo de distúrbio circulatório local, provocando possivelmente menos isquemia ou evitando até necrose das bordas teciduais ${ }^{20}$. Nos animais do grupo III, sob as condições desfavoráveis causadas pela desvascularização da curvatura menor, o trauma provocado pelo tipo de sutura, sobretudo no lado da curvatura menor, poderia aumentar o potencial para o desenvolvimento de complicações isquêmicas. No presente estudo, se a desvascularização da curvatura menor do estômago pela VGP produziu uma isquemia relativa sobre a anastomose gástrica, a intensidade do processo isquêmico não foi suficiente para provocar lesões isquêmicas na linha de sutura. A ausência de deiscência 
de anastomose demonstrou que o chul eio simples contínuo em plano único é um procedimento seguro, mesmo em condições adversas. A fístula anastomótica pós-operatória observada por Nilsell et al. ${ }^{16}$, após GS associada com VGP, desenvolveu-se em anastomose gástrica término-terminal em dois planos de sutura. Embora os autores não tenham afastado outros problemas de ordem técnica, o uso de sutura em dois planos é potencialmente mais isquêmico, como já previamente determinado ${ }^{21}$.

$\mathrm{Na}$ realização dos procedimentos operatórios, cuidados técnicos foram tomados durante as ligaduras dos feixes neurovasculares, prescindindo-se também do uso da el etrocoagulação para evitar que fossem produzidas lesões inadvertidas na curvatura menor do estômago. Nyhus ${ }^{22}$ advertiu sobre as conseqüências da lesão traumática da parede gástrica, sobretudo na área desvascularizada, durante a realização de VGP. Kobayasi et al. ${ }^{23}$ verificaram que o traumatismo na área desvascularizada da curvatura menor do estômago, em cães submetidos à VGP, pode causar complicações isquêmicas, inclusive com o desenvolvimento de perfuração e peritonite.

Na presente investigação, os animais foram sacrificados no tercei ro e no oitavo dias pós-operatório porque as complicações isquêmicas observadas na curvatura menor do estômago, conseqüentes à VGP, foram observadas geralmente no período entre o terceiro e o sétimo dia pós-operatóri o $^{24-29}$.

Considerando as alterações macroscópicas e microscópicas inespecíficas observadas no presente estudo, os achados histopatológicos poderiam estar relacionados diretamente ao trauma sobre a curvatura menor conseqüentes à manipulação ci rúrgica e à isquemia decorrente da extensão da desvascularização gástrica, ou a ambos.

Nos animais do grupo III, embora não fosse incluído a área da anastomose gástrica no fragmento histológico, as alterações morfológicas observadas poderiam ser conseqüentes à resposta local dos tecidos à lesão tecidual pel a contigüidade ao processo de cicatrização da ferida. As alterações microscópicas nas anastomoses gastrointestinais têm sido igualmente caracterizadas por edema, congestão vascular, neoformação capilar, exsudato inflamatório, proliferação fibroblástica e fibrose ${ }^{21,30}$. Com base na semel hança dos achados histopatológicos do presente estudo com as alterações que acompanham os processos de cicatrização das anastomoses gastrointestinais, a intensidade do trauma tecidual provocado pel os procedimentos operatórios também não pôde ser afastada como fator causal.

Por outro lado, será que podemos considerar que as alterações histopatológi cas observadas nos animais submetidos à VGP isolada, achados estes muito semel hantes aos do grupo III , sejam apenas conseqüente ao trauma causado pela desvascularização da curvatura menor? Chiu et al. ${ }^{31}$ estudaram as modificações histopatológicas seqüenciais da mucosa intestinal de cães em condições de baixa perfusão sangüínea, observando alterações estruturais proporcionais à redução do fluxo sangüíneo mesentérico. Estabeleceram ainda uma classificação conforme a gravidade das alterações morfológicas, indo desde acúmulos de líquidos subepiteliais e congestão capilar; seguidos de descolamento do epitélio da lâmina própria, desnudamento das vilosidades e dilatação dos capilares expostos; e, final mente, digestão e desintegração da lâmina própria, com subseqüente hemorragia e ulceração. Esses achados microscópicos seqüenciais foram corroborados por outros estu$\operatorname{dos}^{32,33}$. Ming \& Bonadarpour ${ }^{34}$, ao induzir isquemia sem provocar infarto da alça intestinal, por ligadura e secção de um ramo da artéria mesentérica superi or de cães, verificaram que as alterações microscópicas intestinais ocorreram principalmente nas camadas mucosa e submucosa, sendo a sua natureza determinada pelo intervalo entre o insulto isquêmi co e o sacrifício. Em estudo experimental semelhante, observou-se no segmento intestinal isquêmico, além de outras alterações histopatológicas, infiltrado inflamatório na mucosa, juntamente com edema intersticial e vasos sangüíneos congestos e dilatados na camada submucosa, 15 dias após o insulto isquêmico ${ }^{35}$. No presente estudo, embora o segmento gastrointestinal envolvido tenha sido diferente, os achados histopatológicos foram semel hantes quanto à natureza e ao local de acometimento intramural, com os resultados dos experimentos menci onados anteriormente. Foi observado também uma relação diretamente proporcional entre a gravidade das alterações morfológicas e os procedimentos cirúrgicos de maior potencial isquêmico. Além disso, a persistência da congestão vascular, apesar da tendência de regressão do edema, exsudato inflamatório e dano celular nos animais dos subgrupos II8 e III-8, quando confrontados com os animais do subgrupo II-3 e III-3, sugere que a congestão vascular não poderia ser decorrente apenas do processo inflamatório cicatricial, mas também conseqüente ao processo isquêmico.

No presente estudo, a fibrose foi mais intensa nos animais dos grupos II e III sacrificados no oitavo dia pós-operatório, sugerindo que as alterações inflamatórias observadas mais freqüentemente no terceiro dia pós-operatório evoluíram 
para teci do fibroso, com o aumento do intervalo de tempo entre a operação e o sacrifício, indicando características de cronicidade. Ming \& Bonadarpour ${ }^{34}$, ao avaliar a evol ução cronológica das lesões isquêmicas intestinais de cães, observaram também fibrose na camada submu cosa, com o aumento do período entre o insulto isquêmico e o sacrifício, a qual se estendeu além das áreas evidentes de mucosa regenerada. $\mathrm{Holm}$ et al. ${ }^{36}$, após a desvascularização do estômago por ligaduras de 90 \% do suprimento arterial, observaram uma mucosa gástrica com estroma frouxo e edematoso nos cães sacrificados entre 11 e 22 dias. Cerca de sei s a sete semanas após a isquemia, verificou-se a formação de uma estrutura fibrosa densa, especialmente na região subepitelial.

No presente experimento, a combinação da GS com a VGP, ao seccionar as comunicações vasculares da parede gástrica, impedindo a circulação intramural entre os vasos extrínsecos direito e esquerdo do estômago, possivelmente provocou maior redução do fluxo sangüíneo da curvatura menor do remanescente gástrico proximal, em comparação com a área correspondente dos animais submetidos excl usi vamente à VGP. O suprimento sangüíneo do remanescente gástrico proximal, após VGP associada à GS, foi potencialmente menor do que aquela observada no coto gástrico, após gastrectomia subtotal distal, pois a liberação do esôfago abdominal, seguindo os preceitos técnicos da VGP, constituiu fator de restrição adicional do suprimento sangüíneo, ao interromper os ramos descendentes da artéria esofagiana torácica inferior e de alguns ramos gástricos oriundos da artéria frênica inferior esquerda, como descrito por Couinaud ${ }^{37}$.

Embora seja uma complicação pós-operatória incomum da gastrectomia subtotal distal, diversos casos de necrose isquêmica do coto gástrico foram descritos na literatura ${ }^{38-41}$. E m pacientes com circulação deficiente submetidos à GS, Barber ${ }^{42}$ enfatizou sobre a possibilidade de necrose do segmento gástrico proximal. Por conseguinte, a associação da VGP à GS apresenta potencial para o surgimento de complicações isquêmicas no remanescente gástrico, sobretudo no lado da curvatura menor.

Diante da mai or gravidade das alterações morfológicas observadas nos animais do grupo III, e considerando que essas modificações estruturais não podem ser apenas decorrentes do processo de cicatrização, mas também conseqüente à isquemia, a GS possivelmente agravou o suprimento sangüíneo arterial da parte remanescente da curvatura menor do estômago, já previamente com- prometida pela desvascularização conseqüente à vagotomia gástrica proximal. A maior gravidade da isquemia, decorrente da combinação dos procedimentos cirúrgicos seria o fator causal da maior congestão vascular e das alterações histopatológicas observadas na curvatura menor dos animais do grupo III. De outro Iado, a VGP, ao determinar menor grau de isquemia, explicaria as alterações morfológicas menos intensa observadas nos animais do grupo II, indicando até certo ponto uma relação proporcional entre os achados histopatológi cos e a intensidade do processo isquêmico.

E m preparações de estômagos de cães submeti dos a redução mecânica do fluxo sangüíneo, Bowen \& $\operatorname{Garg}^{43}$, considerando as medidas da tensão de oxigênio intracelular e da diferença de potencial el étrico transmembrana em células epiteliais de mucosa, sugeriram a existência de fatores de segurança na circulação gástrica, os quais permitem a redução de $60 \%$ no fluxo sangüíneo gástrico sem interferência no metabolismo da mucosa por deficiência de oxigênio intracelular.

No presente estudo, como não houve o desenvolvimento de necrose tecidual, conclui-se que não foi ultrapassado o nível crítico de redução no suprimento sangüíneo. Após a GS associada à VGP, a eficiência dos mecanismos compensatórios gástricos, através de uma rica rede de ramos anastomóticos intramurais, foi ainda suficiente para a manutenção da vitali dade da parede gástrica, impedindo o desenvolvimento de complicações isquêmicas. Todavia, qualquer fator agravante do processo isquêmico, tais como circunstâncias anatômicas da curvatura menor desfavoráveis, condições clínicas do paciente, doenças associadas, lesões inadvertidas durante a realização dos procedimentos operatórios e o acréscimo de procedimentos cirúrgicos complementares, ao exceder a capacidade de compensação circulatória, transpondo o limiar crítico, poderá determinar o desenvolvimento de necrose tecidual na área desvascularizada da curvatura menor.

\section{SUMMARY}

\section{Morphologic changes of the lesser gastric curvature after segmental gastrectomy as- sociated to proximal gastric vagotomy. Experimental study in dogs.}

The segmental gastrectomy of the body of the stomach, combined with proximal gastric vagotomy, has been indicated in the treatment of duodenal ulcer, especially in patients with major risk of the recurrent ulceration.

Purpose. To evaluate the histopathologic chan- 
ges, secondaries to combined corporeal segmental gastrectomy and proximal gastric vagotomy, in the lesser curvature of the stomach.

Methods. Thirty-six adult mongrel dogs weighing between 10 to $20 \mathrm{~kg}$ were divided into three groups of twelve animals each: Group I animals (control) were submitted to laparotomy and gastric manipulation; Group II, animals underwent proximal gastric vagotomy; and Group III, animals underwent corporeal segmental gastrectomy combined with proximal gastric vagotomy. Each group was subdivided into two subgroups of six animals each, and according to the subgroup, the animals were then sacrificed on the third or in the eighth postoperative day. A fragment of the lesser curvature was removed from each stomach for microscopic study.

RESULTS. Regarding edema, vascular congestion, inflammatory exudate, fibrosis and cell damage; histopathologic changes found in animals sacrificed in the same postoperative day were sl ight in Group I, moderate in Group II and intense in the group III. Although nonspecific, the character and site of the lesions were similar to the ones occurring in ischemic process. It was also observed a directly proportional relation betwen severity of morphologic changes and ischemic potentiality of surgical procedure.

CONCLUSION. The segmental gastrectomy probably aggravated the arterial blood supply of the remnant of lesser curvature of the stomach, which was already compromised by desvascularization consequent to proximal gastric vagotomy. [Rev Ass Med Bras 2000; 46(2): 126-33]

KEY WORDS: Duodenal ulcer. Gastrectomy. Proximal gastric vagotomy.

Trabalho parcialmente financiado pela CAPES.

\section{REFERÊNCIAS BIBLIOGRÁFICAS}

1. Schirmer BD. Current status of proximal gastric vagotomy. Ann Surg 1989; 209:131-148.

2. J ohnston D. Operative mortality and postoperative morbidity of highly selective vagotomy. Br Med 1975; 4: 545-547.

3. J ordan J r PH; Thornby J. Should be parietal cell vagotomy of selective vagotomy-antrectomy for treatment of duodenal ulcer? A progress report. Ann Surg 1987; 205:572-90

4. Stael von Holstein C, Graffner H, Oscarson J. One hundred patients ten years after parietal cell vagotomy. Br J Surg 74; 101-3, 1987.

5. Goligher J C, Hill, GL, Kenny TE, Nutter E. Proximal gastric vagotomy without drainagefor duodenal ulcer: results after 58 years. Br J Surg 1978; 65: 145-51.

6. Donahue PE, Richter HM, Liu KJ M, Anan K, Nyhus LM. Experimental basis and cl inical application of extended highly selective vagotomy for duodenal ulcer. Surg Gynecol Obstet 1993; 176: 39-49.
7. Koo J , Lam SK, Chan P, Lee NW, Lam P, Wong J. Proximal gastric vagotomy, truncal vagotomy with drainage, and truncal vagotomy with antrectomy for chronic duodenal ulcer. A prospective, randomized controlled trial. Ann Surg 1983; 197: 265-71.

8. Madsen $P$, Kronborg $O$. Recurrent ulcer $5 \frac{1}{2}-8$ years after highly selective vagotomy without drainage and selective vagotomy with pyloroplasty. Scand J Gastroenterol 1980; 15: 193-9.

9. Poppen B; Delin A. Parietal cell vagotomy for duodenal and pyloric ulcers. I. Clinical factors leading to failure of the operation. Am J Surg 1981; 141: 323-9.

10. H offmann J , J ensen H-E, Christiansen J , Olsen A, Loud FB, $\mathrm{H}$ auch $\mathrm{O}$. Prospective controlled vagotomy trial for duodenal ulcer. Results after 11-15 years. Ann Surg 1989; 209: 40-5.

11. Ceneviva R. Gastrectomia segmentar associada à vagotomia supersel etiva notratamento das úlceras duodenais. Rev Assoc Med Bras 1978; 24: 301-2.

12. Oliveira RB, Ceneviva R, Troncon LEA, Silva J r OC, Meneghelli UG. The effect of a segmental gastrectomy with proximal gastric vagotomy on gastric secretion and gastric emptying. Br J Surg 1984; 71: 431-4.

13. Silva, OC. E feitos da associação da gastrectomia segmentar à vagotomia gástrica proximal nas funções gástricas de acomodação à distensão e de esvaziamento de líquidos e sólidos. Ribeirão Preto, 1988. 143p. Tese (Doutorado) - F aculdade de Medicina de Ribeirão Preto da Universidade de São Paulo.

14. Andrade J I, Troncon LEA, Ceneviva R, Morais EN, Chen TH. Quantitative assessment of duodenogastric reflux with $99 \mathrm{~m}-$ Technetium-DISIDA after segmental gastrectomy plus proximal gastric vagotomy. Res surg 1992; 4: 46-9.

15. Ceneviva R, Mente ED, Silva J r OC. Ressecção gástrica segmentar associada à vagotomia gástrica proximal no tratamento da úlcera duodenal. Acta Cir Bras 1997; 12 (Suppl 1): 39-41.

16. Nilsell K, Liljeqvist L, Lindquist $K$. Proximal gastric vagotomy and segmental gastrectomy in duodenal ulcer disease: a preliminary report. Acta Chir Scand 1986; 530 (Suppl): 23-4.

17. Griffith CA, Harkins HN. Partial gastric vagotomy: an experimental study. Gastroenterology 1957; 32: 96-102.

18. Goligher J C. A technique for highly selective (parietal cell or proximal gastric) vagotomy for duodenal ulcer. Br J Surg 1974; 61: 337-45.

19. Hollander, M, Wolfe, DA. Nomparametric statistical methods. New York, J ohn Willy \& Sons, 1973.

20. J ohnson SR. Gastrointestinal anastomosis with a singlelayer of continuous catgut. Acta Chir Scand 1968; 134: 265-8.

21. Mantovani, M, Leonardi, LS, Alcântara, FG, Hadler, WA. Estudo comparativo entre suturas em plano único e em dois planos nointestino del gadona vigência deisquemia. Rev Paul Med 1976; 87: 56-63.

22. Nyhus LM. Comentário editorial. Arch Surg 1978; 113: 207.

23. Kobayasi, S, Rodrigues, MAM, Montenegro, MRG, Macedo, AR, Hossne, WS, Mendes, EF. Necrose da pequena curvatura gástrica após vagotomia gástrica proximal por traumatismo da parede gástrica. Estudo experimental em cães. Re Hosp Clin F ac Med Univ São Paulo 1984; 39: 96-100.

24. Newcombe J F. Fatality after highly selective vagotomy. $\mathrm{Br}$ Med J 1973; 1: 610.

25. Hall R, Summers GAC, Green MA. Complication of proximal gastric vagotomy. Br Med J 1974; 3: 806-7.

26. BrodieSW. Survival after postoperative avascular necrosis of lesser curve of stomach. Br Med J 1975; 3: 229.

27. Halvorsen, J F, Heimann, P, Sol haug, J H, J acobsen, KB. Localized avascular necrosis of lesser curve of stomach complicating highly sel ective vagotomy. Br Med J 1975; 2: 590-1. 
28. Croft RJ . Reperitonealization and invagination of the lesser curvature of the stomach following proximal gastric vagotomy. Arch Surg 1978; 113: 206-7.

29. Takaki A, Yoshino H, Ohkuma R, Ohsato K. Lesser curve necrosis following sel ective proximal vagotomy. A casereport. J pn J Surg 1984; 14: 248-51.

30. Braskén $P$. Healing of experimental col on anastomosis. Eur J Surg 1991; suppl566: 4-51.

31. Chiu C-J , McArdle AH, Brown R, Scott HJ , Gurd FN. Intestinal mucosal lesion in low-flow states. I. A morphological, hemodynamic, and metabolic reappraisal. Arch Surg 1970; 101: 478-83.

32. Åhrén C, Haglund U. Mucosal lesions in thesmall intestine of the cat during low flow. Acta Physiol Scand 1973; 88: 541-50.

33. Wagner R, Gabbert H, Höhn P. Ischemia and post-ischemic regeneration of the small intestinal mucosa. A light microscopic and autoradiographic study. Virchows Arch B Cell Pathol 1979; 31: 259-76.

34. Ming S-C, Bonakdarpour A. Evolution of lesions in intestinal ischemia. Arch Pathol Lab Med 1977;101: 40-3.

35. Manzione A, Camargo J C, M el eiro L, Behmer OA, Zanotto A, Tolosa EMC. Alterações estruturais da parede intestinal produzidas pela isquemia segmentar. Rev Assoc Med Bras $1981 ; 27: 177-81$.
36. Holm B, Boyarsky S, MorrioneTG. The effect of experimental devascularization on gastric mucosa. Gastroenterol ogy 1949; 12: 116-21.

37. Couinaud $C$. Nécrose ischémique de la petite courbure de I'estomac après vagotomie supra-sélective. A propos de 2 cas personnels et de 43 observations publiées dans la littérature. J Chir (Paris) 1983;.120: 77-83.

38. Fell SC, Seidenberg B, Hurwitt ES. I schemic necrosis of the gastric remnant. An uncommon complication of radical subtotal gastrectomy. Surgery 1958; 43: 490-500.

39. J ackson PP. Ischemic necrosis of the proximal gastric remnant following subtotal gastrectomy. Ann Surg 1959; 150: 1071-4.

40. Isabella, V, Marotta, E, Bianchi, F. Ischemic necrosis of proximal gastric remnant following subtotal gastrectomy with splenectomy. J Surg Oncol 1984; 25: 124-32.

41. Gleysteen J J , Condon RE. Danger of fundoplication after selective vagotomy and antrectomy. Arch Surg 1984; 119: 334-5.

42. Barber WH. Annular gastrectomy. Further observations on the cause of its failure. Ann Surg 1933; 98: 161-7.

43. Bowen J C, Garg DK. Effect of graded mechanical ischemia on oxygen tension and electrical potential in the canine gastric mucosa. A new experimental modelo.Gastroenterology 1977; 73: 84-8. 